\title{
Characterization and Simulation of the Thermoacoustic Instability Behavior of an Advanced, Low Emissions Combustor Prototype
}

John C. DeLaat and Daniel E. Paxson

Glenn Research Center, Cleveland, Ohio 


\section{NASA STI Program . . . in Profile}

Since its founding, NASA has been dedicated to the advancement of aeronautics and space science. The NASA Scientific and Technical Information (STI) program plays a key part in helping NASA maintain this important role.

The NASA STI Program operates under the auspices of the Agency Chief Information Officer. It collects, organizes, provides for archiving, and disseminates NASA's STI. The NASA STI program provides access to the NASA Aeronautics and Space Database and its public interface, the NASA Technical Reports Server, thus providing one of the largest collections of aeronautical and space science STI in the world. Results are published in both non-NASA channels and by NASA in the NASA STI Report Series, which includes the following report types:

- TECHNICAL PUBLICATION. Reports of completed research or a major significant phase of research that present the results of NASA programs and include extensive data or theoretical analysis. Includes compilations of significant scientific and technical data and information deemed to be of continuing reference value. NASA counterpart of peer-reviewed formal professional papers but has less stringent limitations on manuscript length and extent of graphic presentations.

- TECHNICAL MEMORANDUM. Scientific and technical findings that are preliminary or of specialized interest, e.g., quick release reports, working papers, and bibliographies that contain minimal annotation. Does not contain extensive analysis.

- CONTRACTOR REPORT. Scientific and technical findings by NASA-sponsored contractors and grantees.

- CONFERENCE PUBLICATION. Collected papers from scientific and technical conferences, symposia, seminars, or other meetings sponsored or cosponsored by NASA.

- SPECIAL PUBLICATION. Scientific, technical, or historical information from NASA programs, projects, and missions, often concerned with subjects having substantial public interest.

- TECHNICAL TRANSLATION. Englishlanguage translations of foreign scientific and technical material pertinent to NASA's mission.

Specialized services also include creating custom thesauri, building customized databases, organizing and publishing research results.

For more information about the NASA STI program, see the following:

- Access the NASA STI program home page at http://www.sti.nasa.gov

- E-mail your question via the Internet to help@ sti.nasa.gov

- Fax your question to the NASA STI Help Desk at 301-621-0134

- Telephone the NASA STI Help Desk at 301-621-0390

- Write to: NASA Center for AeroSpace Information (CASI) 7115 Standard Drive Hanover, MD 21076-1320 


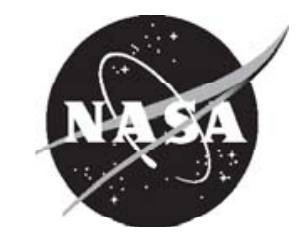

\section{Characterization and Simulation of the Thermoacoustic Instability Behavior of an Advanced, Low Emissions Combustor Prototype}

John C. DeLaat and Daniel E. Paxson

Glenn Research Center, Cleveland, Ohio

Prepared for the

44th Joint Propulsion Conference and Exhibit

cosponsored by the AIAA, ASME, SAE, and ASEE

Hartford, Connecticut, July 21-23, 2008

National Aeronautics and

Space Administration

Glenn Research Center

Cleveland, Ohio 44135 


\section{Acknowledgments}

The authors would like to thank Dr. Changley Wey, test engineer, and all the test operations staff of Test Cell CE5 at NASA Glenn for their help in acquiring the combustor dynamic data. The authors would also like to acknowledge the support received from the NASA Propulsion 21 and Fundamental Aeronautics programs and the program managers John Rohde and Dan Bulzan, respectively.

Trade names and trademarks are used in this report for identification only. Their usage does not constitute an official endorsement, either expressed or implied, by the National Aeronautics and Space Administration.

This work was sponsored by the Fundamental Aeronautics Program at the NASA Glenn Research Center.

Level of Review: This material has been technically reviewed by technical management.

Available from

NASA Center for Aerospace Information 7115 Standard Drive

Hanover, MD 21076-1320
National Technical Information Service 5285 Port Royal Road Springfield, VA 22161 


\title{
Characterization and Simulation of the Thermoacoustic Instability Behavior of an Advanced, Low Emissions Combustor Prototype
}

\author{
John C. DeLaat and Daniel E. Paxson \\ National Aeronautics and Space Administration \\ Glenn Research Center \\ Cleveland, Ohio 44135
}

\begin{abstract}
Extensive research is being done toward the development of ultra-low-emissions combustors for aircraft gas turbine engines. However, these combustors have an increased susceptibility to thermoacoustic instabilities. This type of instability was recently observed in an advanced, low emissions combustor prototype installed in a NASA Glenn Research Center test stand. The instability produces pressure oscillations that grow with increasing fuel/air ratio, preventing full power operation. The instability behavior makes the combustor a potentially useful test bed for research into active control methods for combustion instability suppression. The instability behavior was characterized by operating the combustor at various pressures, temperatures, and fuel and air flows representative of operation within an aircraft gas turbine engine. Trends in instability behavior versus operating condition have been identified and documented, and possible explanations for the trends provided. A simulation developed at NASA Glenn captures the observed instability behavior. The physics-based simulation includes the relevant physical features of the combustor and test rig, employs a Sectored 1-D approach, includes simplified reaction equations, and provides time-accurate results. A computationally efficient method is used for area transitions, which decreases run times and allows the simulation to be used for parametric studies, including control method investigations. Simulation results show that the simulation exhibits a self-starting, self-sustained combustion instability and also replicates the experimentally observed instability trends versus operating condition. Future plans are to use the simulation to investigate active control strategies to suppress combustion instabilities and then to experimentally demonstrate active instability suppression with the low emissions combustor prototype, enabling full power, stable operation.
\end{abstract}

\section{Nomenclature}

$\begin{array}{ll}\text { A } & \text { cross-sectional area } \\ a & \text { speed of sound } \\ \text { amp } & \text { combustor pressure oscillation amplitude } \\ \text { FAR } & \text { fuel/air ratio } \\ \mathrm{K}_{0} & \text { constant proportional to the single-species chemical reaction rate } \\ L & \text { combustor length } \\ \mathrm{P}_{0} & \text { combustor simulation inlet pressure } \\ \mathrm{P}_{3} & \text { combustor inlet pressure } \\ \mathrm{P}_{3 \text { DynB }} & \text { sensed combustor inlet dynamic pressure } \\ \mathrm{P}_{4} & \text { pressure within the combustor } \\ \mathrm{P}_{4 \text { DynUp }} & \text { upstream sensed combustor dynamic pressure } \\ \mathrm{P}_{4 \text { DynDn }} & \text { downstream sensed combustor dynamic pressure } \\ \mathrm{Re}_{\mathrm{T}} & \text { Reynolds number } \\ \mathrm{T}_{0} & \text { combustor simulation inlet temperature } \\ \mathrm{T}_{3} & \text { combustor inlet temperature } \\ \mathrm{W}_{3 \mathrm{c}} & \text { corrected combustor inlet airflow } \\ \mathrm{W}_{3} & \text { combustor inlet airflow } \\ \alpha & \text { maximum diffusion coefficient }\end{array}$




$\begin{array}{ll}\varepsilon_{t} & \text { turbulent viscosity ratio } \\ \phi & \text { equivalence ratio } \\ \mu & \text { molecular viscosity } \\ \rho & \text { density }\end{array}$

\section{Superscripts}

denotes a reference state relevant to the operating point of interest denotes a nondimensional quantity normalized by the reference state

\section{Subscripts}

$\begin{array}{ll}\text { blocked } & \text { denotes a reduced cross-sectional area } \\ \text { flametube } & \text { denotes the cross-sectional area of the downstream part of the combustor } \\ \text { hp } & \text { denotes the higher pressure operating condition } \\ \text { lp } & \text { denotes the lower pressure operating condition } \\ \text { plenum } & \text { denotes the cross-sectional area of the inlet plenum }\end{array}$

\section{Introduction}

\section{A. Background}

Future aircraft engines must provide low emissions and high efficiency at low cost while maintaining the reliability and operability of present day engines. The demands for increased performance and decreased emissions have resulted in advanced combustor designs that are critically dependent on efficient fuel/air mixing and lean operation. However, all combustors, but most notably lean-burning ultra-low-emissions combustors, are susceptible to combustion instabilities. These instabilities are typically caused by the interaction of the fluctuating heat release of the combustion process with naturally occurring acoustic resonances (ref. 1). If not mitigated, these interactions can produce pressure oscillations within the combustor that could reduce component life and potentially lead to premature mechanical failures.

Combustor instability has been a persistent issue in ground-based gas turbines using premixed combustors (ref. 2) and will likely become more challenging as aero-engine combustor development continues to move toward leaner direct injection schemes. High-frequency combustion instabilities are likely due to the relatively short aero-engine combustor geometries. Effective suppression of these instabilities is a critical enabling technology for lean-burning ultra-low-emission combustors and requires several key issues to be addressed. First, dynamic models are needed for understanding the instability phenomenon and also for developing controls. Sensors and algorithms able to detect and interpret the instability need to be developed. Devices that can introduce controlled-perturbations into the combustor to produce a change in the instability are needed. And lastly, suitable control algorithms are needed to drive the actuators to mitigate the instability.

In recent years, there has been considerable activity addressing Active Combustion Control. Government, academia, and industry research efforts, through analysis and the use of laboratory combustors, have shown the considerable potential for active control (refs. 3 to 12). The NASA Glenn Active Combustion Control Technology activity aims to demonstrate active control in a realistic environment relevant to aircraft engines by providing experiments tied to aircraft gas turbine combustors. The intent is to allow the technology maturity of active combustion control to advance to eventual demonstration in an engine environment. Previous work at NASA Glenn has shown that active combustion control, utilizing advanced algorithms working through high frequency fuel actuation, can effectively suppress instabilities in a combustor which emulates the instabilities found in an aircraft gas turbine engine (refs. 13 to 15). It is desired to extend these active control methods to advanced ultra-lowemissions combustors such as those employing multi-point lean direct injection (ref. 16). 


\section{B. Description of the Current Effort}

In order to continue to mature the active combustion control and related technologies, a near term, but technically advanced low emissions combustor test bed is desired. Recently, emissions testing of an advanced low-emissions combustor prototype was performed in one of the combustion test cells at the NASA Glenn Research Center. During this testing, combustion instability pressure oscillations were observed. In addition, the instability pressure oscillations were observed to grow with increasing fuel/air ratio (FAR). This instability growth prevented the combustor from reaching full power operation. The effort described in this paper acquired dynamic data from that combustor and analyzed that data in order to characterize the instability behavior of the combustor. Specifically, trends in instability amplitude versus operating conditions were observed and documented. The goal of the dynamic characterization was to identify conditions where the combustor prototype can serve as a suitable test bed for active controls research.

A combustion instability simulation, previously developed at NASA Glenn (ref. 17), has been modified to capture the specific geometry and operating conditions of the advanced combustor prototype. The simulation layout embodies the relevant physical features of the combustor and test rig in order to provide a simulation of the experimentally observed instability behavior. The simulated combustion instability closely matches that of the combustor for steady fuel flow and also replicates the growth in instability amplitude as the FAR is increased.

In future efforts, this simulation is planned to be used for combustion control development. It is hoped that the control methods thus developed will be able to experimentally mitigate the combustion instability in the advanced combustor prototype and, in so doing, enable full power operation.

This paper describes the effort to dynamically characterize and then simulate the instability behavior of this advanced, low emissions combustor. First, the combustor experiment is described including the type of testing performed and the locations and type of dynamic instrumentation. Initial observations about the instability behavior are given, followed by a more detailed analysis of how the instability changes with changes in operating conditions of the combustor. The combustor prototype is shown to be a suitable test bed for active instability control research. The simulation method employed to capture the combustor instability is then described, including details for this particular combustor. Finally, it is shown that this simulation successfully captures the instability behavior, and is ready to be utilized for control method development in preparation for experimental demonstration of combustion instability control with the research combustor.

\section{Description of the Low Emissions Combustor Prototype Experiment}

Several advanced low emissions combustor concepts for aircraft gas turbine engines have been developed in conjunction with NASA's industrial partners. It was during emissions testing of one of these advanced combustor prototypes that thermoacoustic instability was observed. The combustor prototype consists of a pilot and main stage. The pilot operates locally rich and the main stage operates locally lean, however the overall FAR is always lean with typical equivalence ratio of $\phi=0.3-0.5$ (FAR=0.02-0.034). The combustor is installed in a flame tube in test cell CE5 at NASA Glenn (fig. 1). The test series being conducted was primarily to obtain emissions data from the combustor prototype. The emissions data collected is not the subject of this paper. However, during that test series, the combustor was also instrumented with dynamic pressure transducers at the locations shown in figure 1 . There were two water cooled dynamic (AC-coupled) pressure transducers upstream of the fuel injector. One of these transducers provided useful data $\left(\mathrm{P}_{3 \mathrm{DynB}}\right)$, the other had an unresolved electrical problem. Downstream of the fuel injector, two uncooled dynamic pressure transducers $\left(\mathrm{P}_{4 \text { Dynup }}, \mathrm{P}_{4 \mathrm{DynDn}}\right)$ were installed in a purged, semiinfinite line configuration in order to isolate the transducers from the hot combustion products. The downstream transducer, $\mathrm{P}_{4 \mathrm{DynDn}}$, had less background noise and is used for most of the analysis in this paper. 


\section{A. Test Results and Data Analysis for the First Test Run}

The first objective of the instability characterization was to confirm the observed trend of increasing instability amplitude with increasing FAR. Post-test processing of the dynamic pressure data was conducted to confirm this trend. For all of the analysis shown, combustor dynamic pressure data were acquired with a sample time of $5 \mathrm{KHz}$. For steady fuel flow conditions, $10 \mathrm{sec}$ of data were typically acquired. The data were processed to obtain a power spectral density of the pressure. The MATLAB PSD function, which implements Welch's method, was applied to the data. An FFT length of 4096 was used and the data were segmented with a Hanning window of length 4096 and a window overlap of 75 percent of the window size. The spectral data were scaled to provide spectral amplitude in psi. Figure 2 shows combustor dynamic pressure data for four different fuel/air ratios with a fixed combination of inlet pressure, inlet temperature, and air flow. The plots on the left of the figure show the amplitude spectra for the combustor dynamic pressure. The plots on the right side of the figure show a section of the time history data on which the amplitude spectra are based. Note that for the spectral data the y-axis scale varies in order to be able to see the features in the data. From the amplitude spectra it can be readily seen that as the FAR increases, the instability peak at around $530 \mathrm{~Hz}$ also increases. The increase in amplitude of the roughly sinusoidal pressure oscillations can also be seen in the time history data. This initial analysis of the time history data confirmed what had been observed with the spectrum analyzer instrument and prompted further investigation into the trends in instability amplitude versus operating condition. It can also be seen in figure 2 that the frequency of the instability increases with increasing FAR. This possible trend prompted further investigation into the relationship between frequency and FAR as discussed later in section III.B.
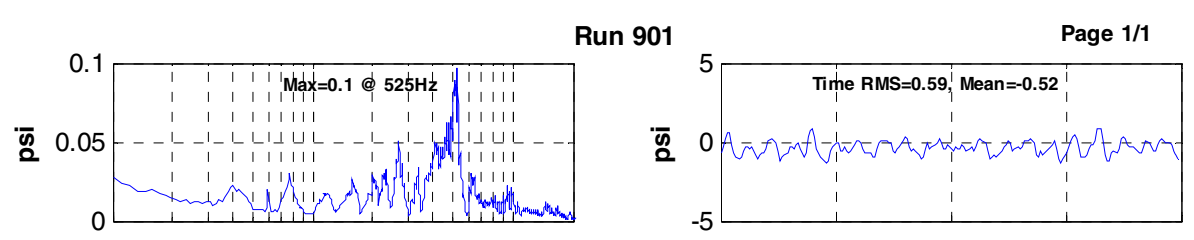

Increasing FAR
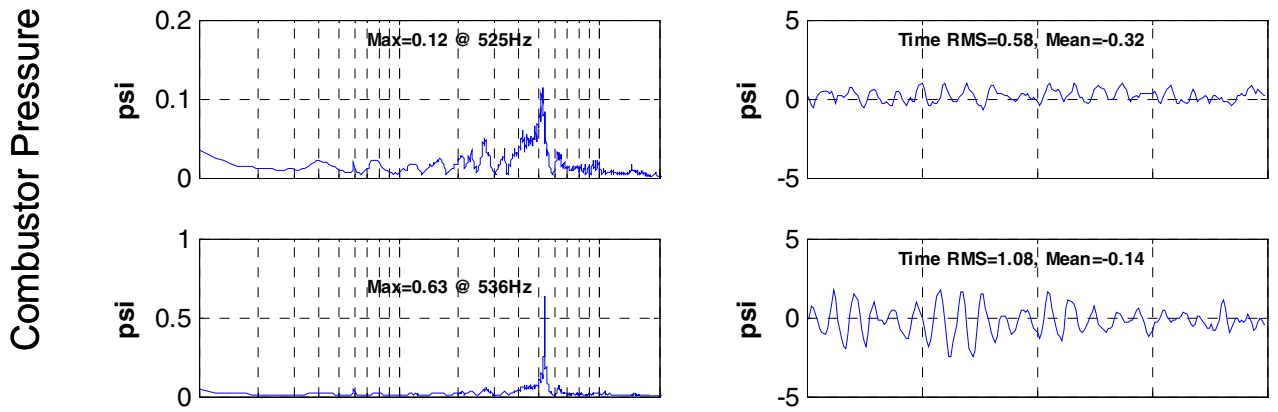

0.025

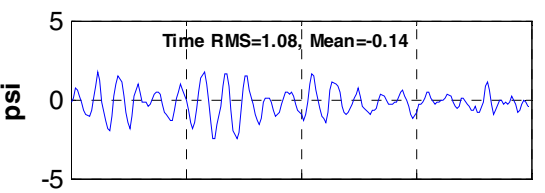

0.0252
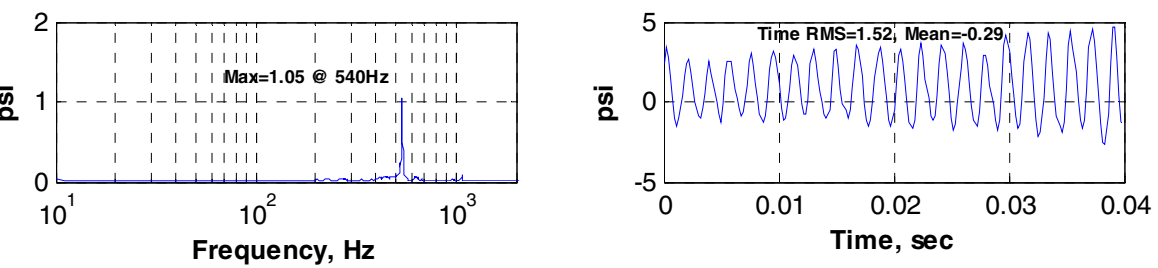

0.0281

0.029

Figure 2.-Instability amplitude for four different fuel/air ratios. The left plots are combustor pressure amplitude spectra in psi and the right plots are time history data for the combustor dynamic pressure. Combustor operating conditions are: inlet pressure $250 \mathrm{psia}$, inlet temperature $1000^{\circ} \mathrm{F}$, airflow $3.4 \mathrm{lbm} / \mathrm{s}$, with pilot/main fuel split percentage 10/90. Fuel/air ratio is shown to the right of each pair of plots. 


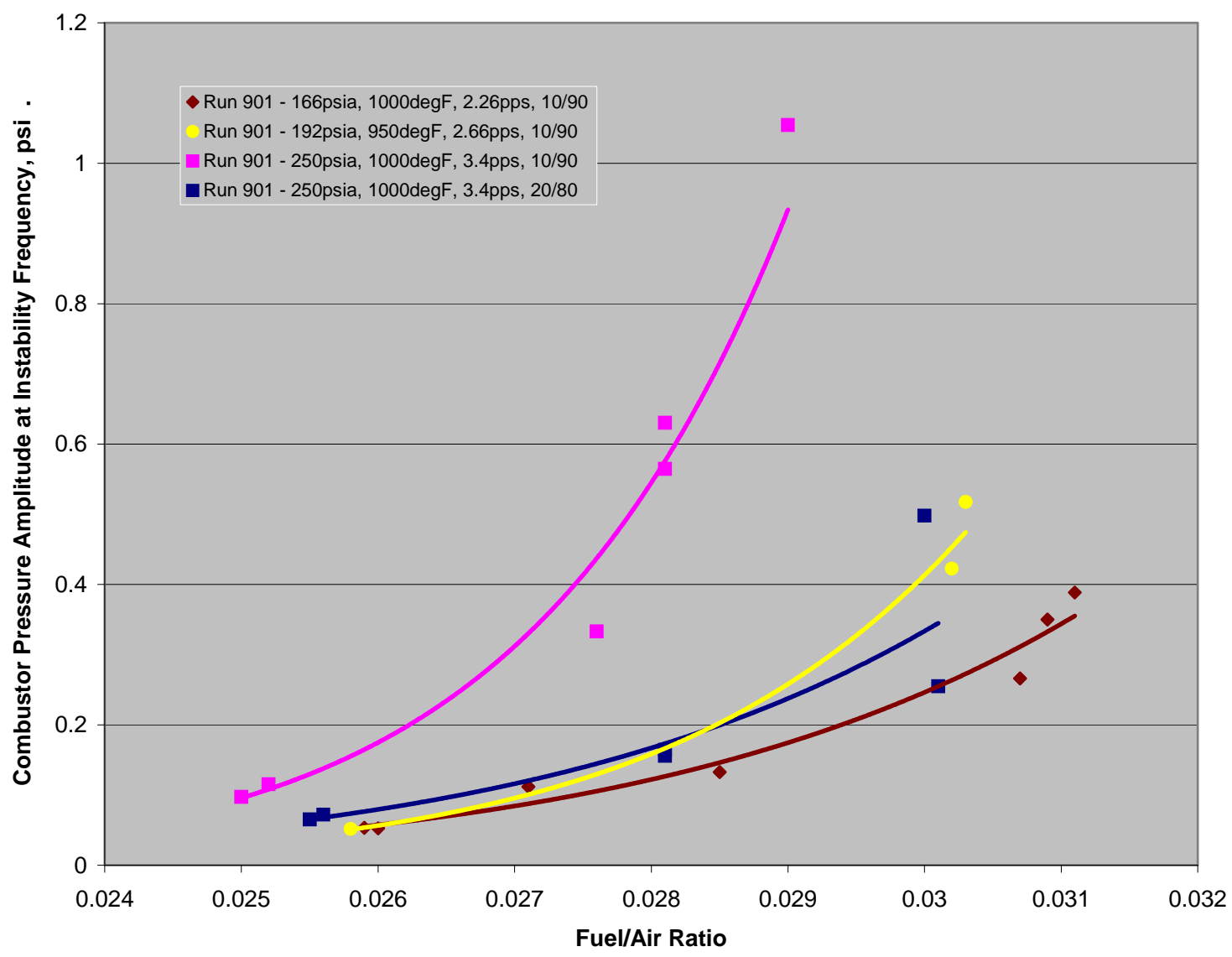

Figure 3.-Combustor pressure peak instability amplitude versus fuel/air ratio for initial test run.

In addition to the data shown in figure 2, dynamic pressure data were acquired for multiple FARs at two other inlet pressure/temperature/airflow conditions. Also, for the same flow conditions shown in figure 2, dynamic pressure data were acquired for a pilot/main fuel split percentage of 20/80. For the first day of testing, 23 different dynamic data points were acquired and analyzed.

Initially, it was felt that the RMS value of the time history data might be a good indicator of the amount of instability present. However, examining the RMS values for the data points taken showed that the RMS value did not necessarily increase along with the instability. This was because the RMS value embodies the power at all frequencies. For example, if a large (relative to the instability), low frequency facility pressure oscillation occurred during a data point, the RMS value could be large, independent of the size of the instability. So, instead of RMS, it was decided that the peak value at the instability frequency, that is, the peak value of the amplitude spectra, would be used as the indicator of the size of the instability.

A plot of the peak value at the instability frequency of the combustor pressure for all 23 of the data points from the initial test run is shown in figure 3. (A simple curve-fit has been added for each set of data points to aid identification of trends in the data.) While there is some scatter in the data, several observations can readily be made from this plot. First, the trend from figure 2 of increasing instability amplitude with increasing FAR is now quite obvious (the peak values for the data shown in fig. 2 are the left-most points (magenta squares) in fig. 3). This instability amplitude trend can be seen to be present for all three of the inlet pressure/temperature/airflow conditions shown. A second observation is that the sensitivity to FAR tends to increase as inlet pressure (and thus airflow) increases, that is, the instability 
amplitude increases more quickly with FAR as the inlet pressure/airflow increases. The third observation pertains to pilot/main fuel split percentage. Note that three of the four sets of data points shown in figure 3 have a pilot/main fuel split percentage of 10/90. However, one set of data from this initial run was acquired with the pilot/main fuel split percentage at 20/80. For this set of data points (the dark blue squares in fig. 3), the same trend in instability amplitude versus FAR is also observed. However, it can be seen that increasing the percentage of the fuel flow through the pilot (going from 10/90 to 20/80 split) reduces the amplitude and sensitivity of the instability to FAR, that is, it tends to stabilize the combustor.

\section{B. Test Results and Data Analysis for Additional Test Runs}

Dynamic pressure data were also acquired during two other test runs with the low emission combustor prototype. These additional sets of data were processed in a fashion similar to that previously described and the peak values of the combustion pressure oscillations at the instability frequency obtained. In all, 82 data points were obtained consisting of 11 sets of instability amplitude versus FAR data at five different inlet pressure/temperature/airflow conditions (see fig. 4). Included were repeats during later test runs of the four sets of data shown in figure 3 . These are shown in figure 4 as hollow symbols with dashed-line curve fits.

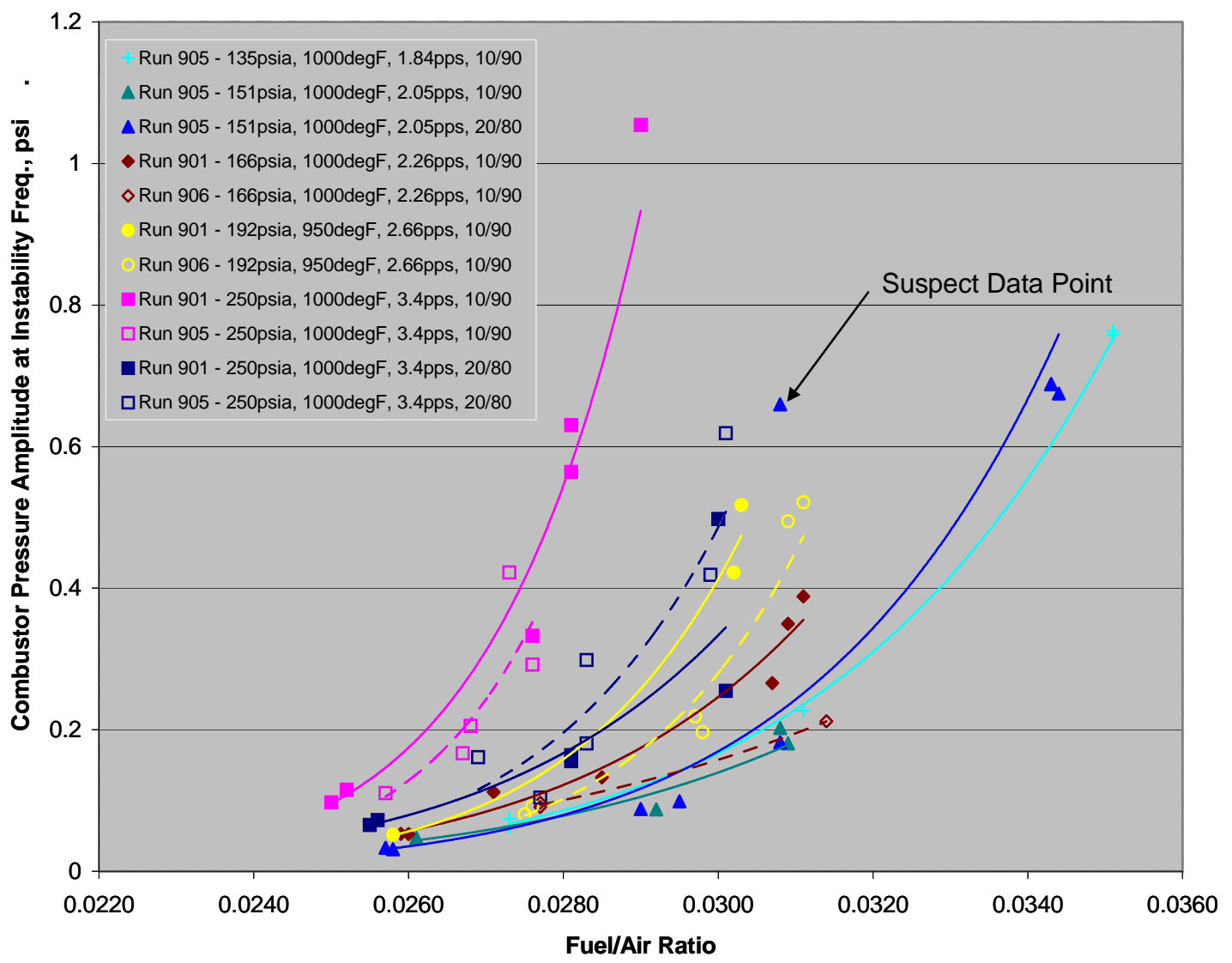

Figure 4.—Combustor pressure peak instability amplitude versus fuel/air ratio for multiple test runs. 
The overall trend of instability peak amplitude increasing as the square of FAR can be seen in all the data sets. The tendency toward an increase in sensitivity to FAR as airflow increases is also seen for the larger number of inlet pressure/temperature/flow variations shown in figure 4. However, the trend becomes less obvious at the lower airflows. The decreased instability amplitude and decreased sensitivity for increased pilot fuel flow percentage can be seen in figure 4 for the repeated test data at the high pressure/airflow condition (inlet pressure $=250$ psia). However, for the other point where a 20/80 fuel split percentage was run (inlet pressure $=151 \mathrm{psia}$ ), the difference in amplitude/sensitivity is not apparent. While there is an outlier in the 20/80 data for the low airflow condition which influenced the curve fit (see the "Suspect Data Point" in fig. 4), the other data points still do not show a significant difference between the $10 / 90$ and the 20/80 data. This seems to imply that the decreased sensitivity to FAR changes as inlet pressure/airflow are decreased may also carry over into a decreased sensitivity to changes in fuel flow split.

Next, the frequency at which the peak in instability amplitude occurs was obtained for all eighty-two test points. These instability frequencies versus FAR for all the same data points as in figure 4 are shown in figure 5. While there seems to be more scatter in the data, a trend where instability frequency increases as FAR increases can still be seen for all the sets of data. The frequency would appear to increase roughly linearly with FAR. In addition, it can be seen that the instability frequency generally increases with increasing airflow. The sensitivity of frequency to FAR (that is, the slope of the linear curve fit) is generally the same with the exception of one set of data which may have a suspect data point. Interestingly, for both cases where the pilot/main fuel split percentage was changed from 10/90 to 20/80, a higher range of frequencies resulted. Unlike the change in amplitude/sensitivity, this shift up in frequency range occurs for both the high pressure/airflow condition (inlet pressure $=250 \mathrm{psia}$ ) and low pressure/airflow condition (inlet pressure $=151$ psia).

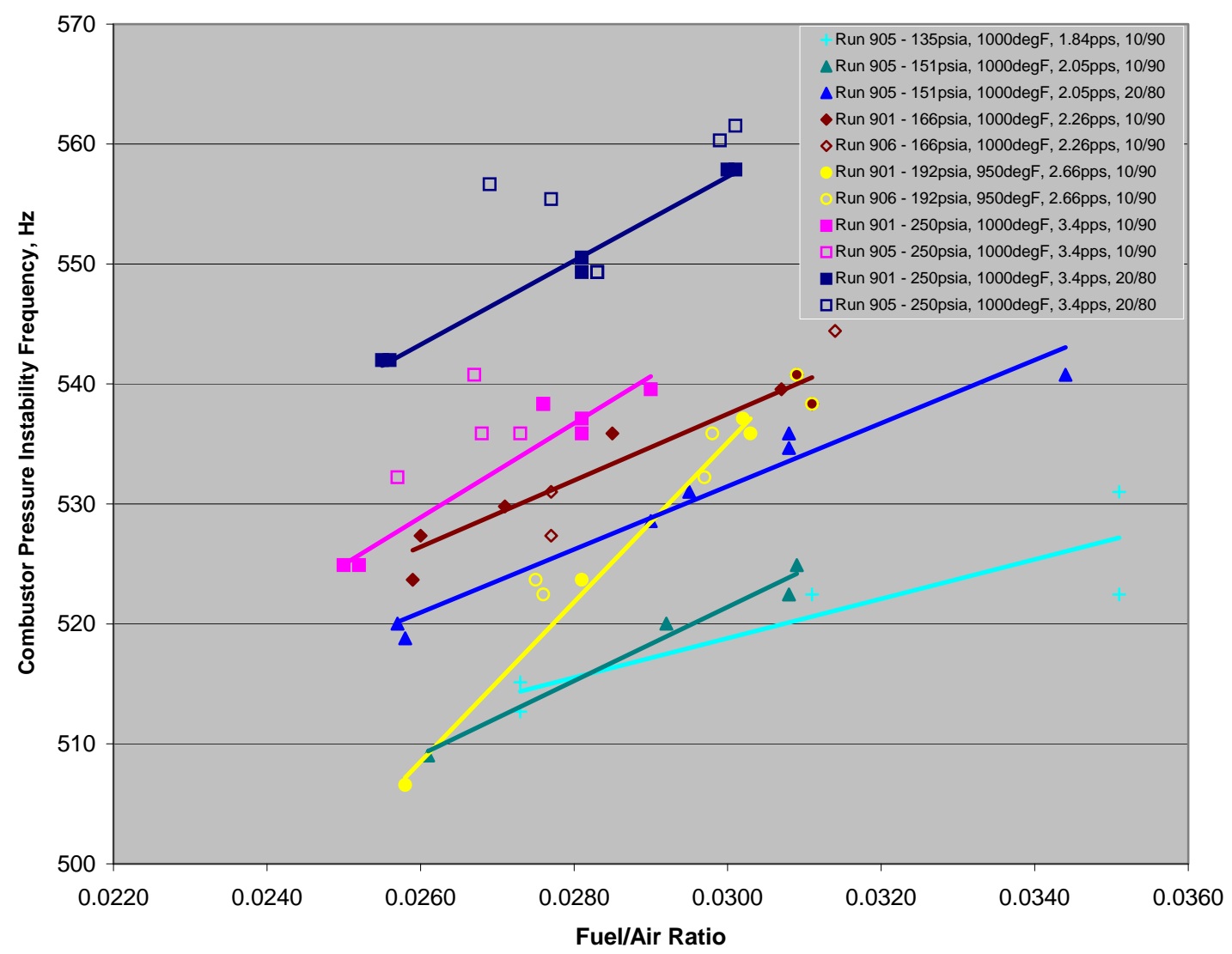

Figure 5.—Combustor instability frequency versus fuel/air ratio for multiple test runs. 


\section{Test Results and Analysis for Transient Fuel/Air Ratio}

Up to this point, all the data discussed has been for (as best as could be maintained) steady conditions including steady fuel flow. In addition to these steady points, a small number of data points were taken with fuel flow being changed transiently from one value to another. No automatic controls were used to change the fuel flow, so the results are not particularly repeatable. However, in order to show how the combustor behaved as FAR was slowly changed, one of these data points is included here.

The spectral and time history data for the combustor dynamic pressure during a fuel flow transient from FAR of 0.0265 to 0.029 are shown in figure 6. The FAR change, shown in the top part of figure 6 was effected by holding the air flow constant and increasing first the pilot fuel flow, and then the main fuel flow. The places where the fuel flow is changing are noted in the figure.

It can be seen from the combustor pressure time history (the middle plot in fig. 6) that there are some low frequency changes in the average value of the combustor pressure and also in the instability amplitude. It is not clear if these are due to variations in the combustor/rig operating conditions, or due directly to the instability and other dynamics in the combustor. These low frequency events aside, it can be seen that the general trend has once again been repeated, that is, the amplitude of the instability increases as the FAR increases. This is evident in the time history of the combustor pressure and also in the spectral history (bottom plot).

The amplitude of the instability for this data point was inadvertently allowed to get quite large ( $\sim \pm$ psi), although the combustor was still not at the full power FAR. As mentioned previously, concern for the health of the fuel injector hardware set a general guideline of not allowing the pressure oscillations to grow beyond \pm 1 psi. For the transient shown, the test operators, on seeing the instability growing, immediately reduced the fuel flow. This provides a direct example of how the instability has limited the combustor from being operated at full power. If the instability could be effectively suppressed, this might enable full power operation of the combustor.

\section{Additional Test Results and Analysis}

There were two other behaviors that were observed in the dynamic pressure data that are noted here. First, in addition to the pilot/main fuel flow percentage data of 10/90 and 20/80 shown previously, there were also points taken with only the pilot operating (100/0). Without exception, these points are quiet, that is, there is no noticeable instability present. This confirmed the preliminary observations noted in section II. The other behavior observed is that for the low inlet pressure/airflow conditions, there tended to be a second peak in the pressure amplitude spectra about $100 \mathrm{~Hz}$ above the instability frequency that would emerge when the FAR was low, but that would tend to be swamped out by the instability as the FAR increased. An example of this behavior is shown in figure 7. As with figure 2, the left plots are amplitude spectra of the combustor dynamic pressure, and the right plots are time history data. Three pairs of plots are shown for three different fuel/air ratios. As can be seen in the figure, for the lowest FAR the instability peak is visible at around $510 \mathrm{~Hz}$ along with a small peak at around $600 \mathrm{~Hz}$. As the FAR is increased, both peaks grow. For the middle FAR shown, the two peaks are similar in size, and beating of the two frequencies can be seen in the time history plot. As FAR continues to increase, the instability continues to grow, while the second peak remains about the size it was for the medium FAR. 

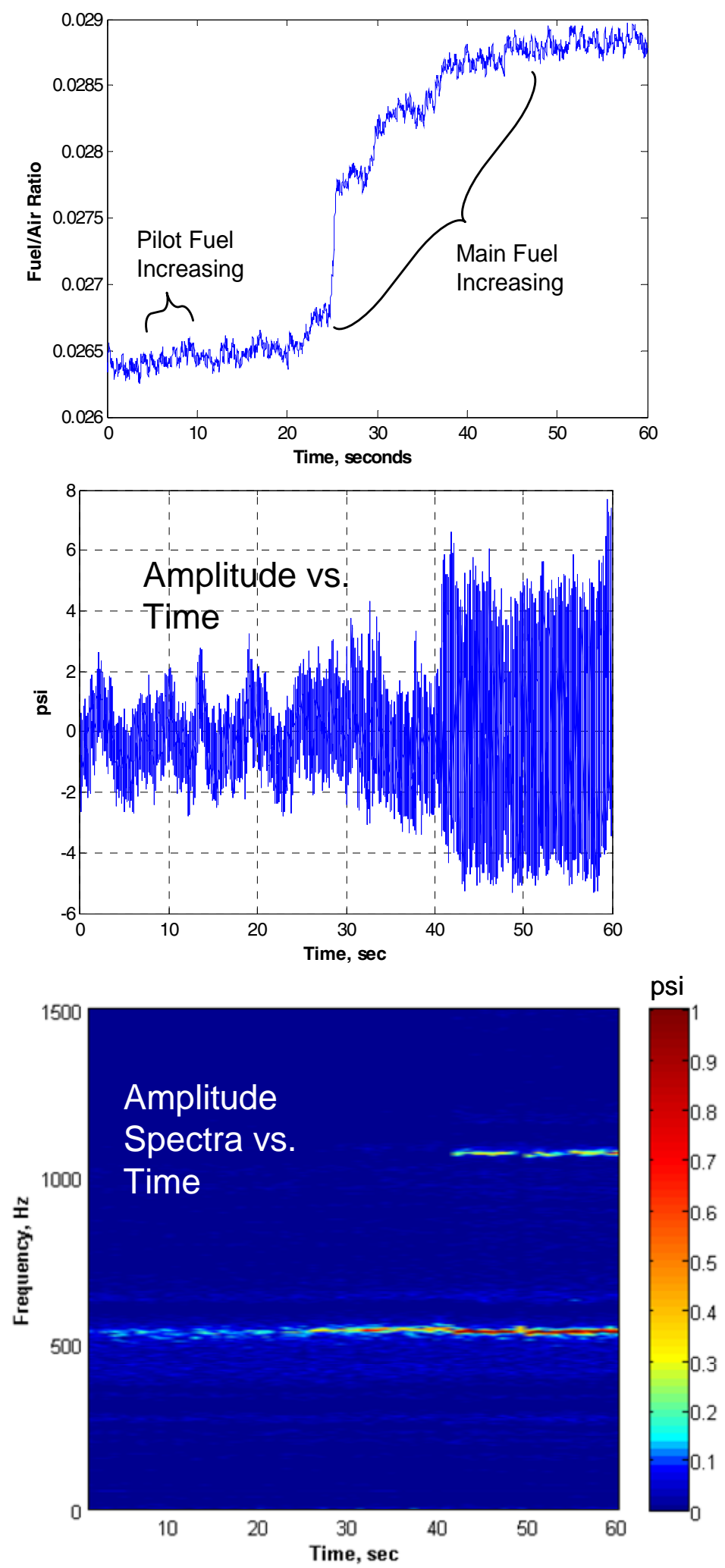

Figure 6.--Instability amplitude change for transiently changing fuel/air ratio. Time history of FAR (top), Time history and amplitude spectra history (middle, bottom) of combustor dynamic pressure for FAR over $60 \mathrm{sec}$ from 0.0265 to 0.029 . 


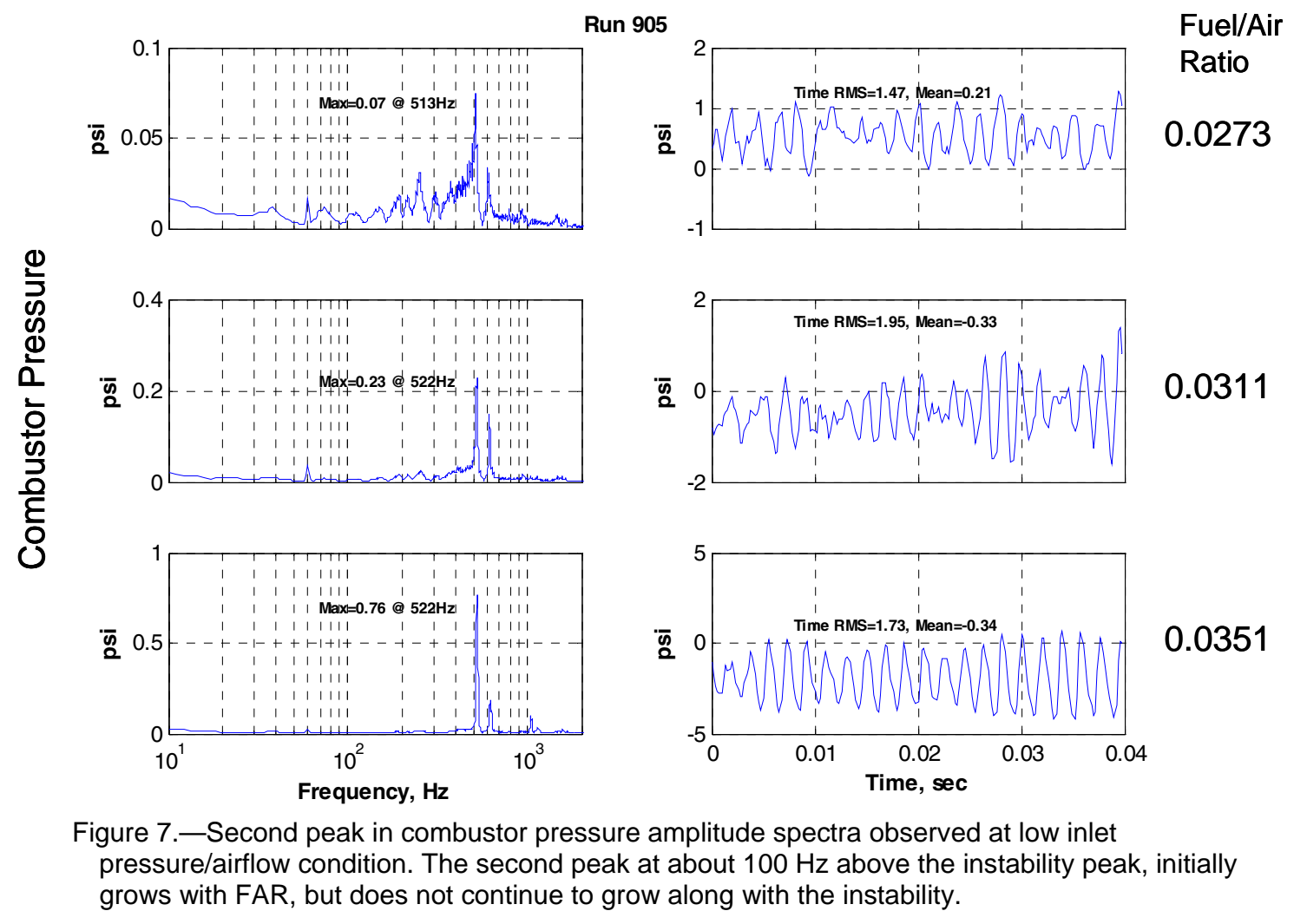

\section{E. Discussion of Test Results}

Remember that the objective of this effort is to identify and characterize a suitable test bed for combustion control research and technology development. As such, it is not necessary to understand in detail the physical phenomena which cause the combustor behavior noted in the previous sections. However, some speculation about the causes of the trends and other behaviors observed can be helpful as attempts are made to control the instability behavior. Related insights gained while attempting to develop a simulation of the instability behavior are discussed in the next section. In the end, understanding a phenomenon is always a good step toward attempting to control it.

The first behavior discussed is the increase in instability amplitude with increasing FAR. This is actually a fairly common behavior and has been noted repeatedly in the literature. It is easy to understand if you think of the combustion instability as a balancing act between the coupled behavior of the acoustics and flame interacting with each other (which tends to make the instability grow), and the damping in the combustor (which tends to make the instability shrink). Sources of damping can include, for instance, an "improper" phase relationship (that is, improper for instability growth) between the heat addition and combustion chamber acoustics, the introduction of cooling and dilution air into the combustor, and thermal non-uniformities in the combustor. Sources of instability growth can include the "proper" phase relationship between the heat addition and combustion chamber acoustics, vortex shedding and other turbulent phenomena generated by the fuel injector, and the energy introduced into the combustor by burning. The latter is proportional to the fuel flow and will increase as the FAR increases for a fixed airflow and can thus cause the instability energy to grow.

The increase in sensitivity to FAR with increasing air flow can also potentially be explained. Since the air flow is increasing, in order to maintain a particular FAR, the amount of fuel must also increase. 
This again is a source of increasing energy introduced into the combustor and therefore a source of additional energy for the instability. This increase in energy, however, may be spread over the additional air volumetric flow which may decrease its effect. Another possible explanation is that the increase in pressure accompanying the increase in airflow provides an increase in reaction rate (ref. 1). This may change the way the heat addition interacts with the acoustics. Admittedly, the thermoacoustic interactions are not yet well understood for this combustor.

The next behavior discussed is the increase in instability frequency with increasing FAR. This seems relatively straightforward to understand. As the FAR is increased, the temperature of the flame increases and thus the temperature throughout the combustor increases. This causes an increase in the speed of sound and an increase in the resonant frequencies that the combustion chamber acoustics will support.

A possible explanation for the double-peaked behavior observed for low airflows can be found by considering possible sources of instability growth in the combustor. Since the fuel injector's swirler (and other physical features of the combustor) are of fixed cross-sectional area, as the inlet pressure (and consequently the inlet airflow) increases, the air velocity increases as well. Thus for the low airflow conditions, where the air velocity is lower, the vortex strength will be greater and you might expect some response in the combustor pressure amplitude spectra. The vortex shedding frequency of the fuel injector/swirler may be independent of the instability frequency, but still be loosely coupled to the instability phenomenon, especially if the frequencies are similar. As such, the vortices may initially sympathize with the instability. However, since the coupling is weak compared to, for instance, the coupling between the acoustics and equivalence ratio, the response at the vortex shedding frequency may not grow to the same extent as the instability.

The fact that pilot-only operation did not support the instability behavior is also consistent with what has been reported elsewhere. The pilot is, by design, a source of stability in the combustor. It operates at an equivalence ratio greater than one and is robust to airflow and air velocity perturbations. Thus, changing the fuel split between the pilot and main stage is often used to stabilize a combustor. It is also well known that the location of the heat addition is an important aspect of instability formation. Since the pilot uses a different geometry, has a different flame structure, and potentially a different flame location, it is understandable that the pilot does not support the instability in the same way that the main stage does.

\section{Combustion Instability Dynamics Simulation}

In order to conduct simulation evaluations of instability control methods, and also to gain insights into the instability phenomenon, a combustion instability simulation method has been developed at NASA Glenn. The simulation layout embodies the relevant physical features of the combustor and test rig. Modifications have been applied to the basic simulation in order to capture the experimentally observed instability behavior of the low emissions combustor prototype described in the preceding sections.

\section{A. General Features of the Combustion Instability Simulation Method}

The physics-based combustion instability simulation uses a Sectored 1-D approach, includes simplified reaction equations, and provides time-accurate results (ref. 17). A computationally efficient method is used for area transitions, which decreases run times and allows the simulation to be used for parametric studies, including control methods investigations. The approach utilizes the one-dimensional Navier-Stokes equations as its basis. In addition to mass, momentum, and energy equations, there is a single species transport equation for the reactant. Associated with these are relatively simple reaction and heat release equations. The governing equations of motion are solved numerically using a very simple, second-order MacCormack scheme. Artificial viscosity is added in order to damp non-physical oscillations in vicinities of strong spatial gradients such as those brought about by the combustion process. The numerical scheme and associated artificial viscosity were chosen because of the computational speed which they afford. Due to the abrupt changes in cross section that are inherent in the 
combustor geometry a sectored approach is used. Here, the combustor is approximated by dividing it into a finite number of one-dimensional (constant area) sectors. Within each sector, the equations of motion and species transport are integrated numerically. Across the sectors, mass and energy are conserved, and momentum loss is prescribed using appropriately compatible boundary conditions that account for the area change. The resulting simulation and associated boundary conditions essentially represent a onedimensional, multi-block technique. This approach has been used to successfully reproduce self-excited instabilities that have been observed in several experimental rigs.

\section{B. Particular Features of the Current Simulation}

The physical layout of the simulation for the low emissions combustor prototype as installed in the NASA flame tube rig is shown in figure 8. The figure shows the relationship between the sectors in the simulation and the components of the combustor and rig. The lengths and cross-sectional areas in the simulation were chosen to match the combustor and rig dimensions. The boundary conditions which can be implemented in the simulation include three types: constant pressure; constant mass flux; and flow with blockage (i.e., flow across an orifice or perforated plate). Each type produces different impedances with which to terminate the computational space. For the present simulation, flow with blockage was used for the inlet end. A blockage ratio of $0.83\left(\mathrm{~A}_{\text {blocked }} / \mathrm{A}_{\text {plenum }}\right)$ was used, which is consistent with the actual perforated plate installed in the rig. The combustor rig exhausts into a duct of approximately 4 times the cross sectional area of the flame tube section. It might seem reasonable therefore to use a constant pressure-type boundary condition here. However, there is a water spray cooling system in the exhaust duct, and the quantity of water sprayed is substantial. While this arrangement can be crudely modeled with the present simulation method, it adds tremendous computing time since the size of the computational domain is substantially enlarged. Instead, it was supposed that the water spray effectively creates a very high density fluid (relative to that in the flame tube) from which acoustic waves generated in the flame tube are largely reflected. In terms of impedance, this type of boundary is similar to outflow with blockage, where the blockage is substantial enough to nearly choke the flow. As such, this was the type of boundary condition implemented at the simulation exit plane. The blockage ratio ( $\left.\mathrm{A}_{\text {blocked }} / \mathrm{A}_{\text {flametube }}\right)$ was 0.885 . The back pressure required to admit the required gas flow rate at the required pressure was 79 percent of the upstream pressure (whereas in order to choke the flow, the back pressure would need to be approximately 55 percent of the upstream pressure). The amplitudes of the thermoacoustic oscillations observed with the simulation were quite sensitive to this exit boundary condition. This will be discussed below.

Noise was introduced into the simulation by means of a momentum source term present only in the numerical cells associated with the fuel injector zone. The source term adds or removes momentum in a random manner each time step. The maximum value which the source terms can achieve is prescribed. It is typically adjusted until the noise floor of the simulation resembles that of the experiment (e.g., as in the amplitude spectrum in fig. 2). The frequency content of the random momentum term is filtered such that fluctuations above $5000 \mathrm{~Hz}$. and below $50 \mathrm{~Hz}$. are removed. This is based on prior experience by NASA and others that shows that the fuel injector tends to only sympathize with certain frequencies. 

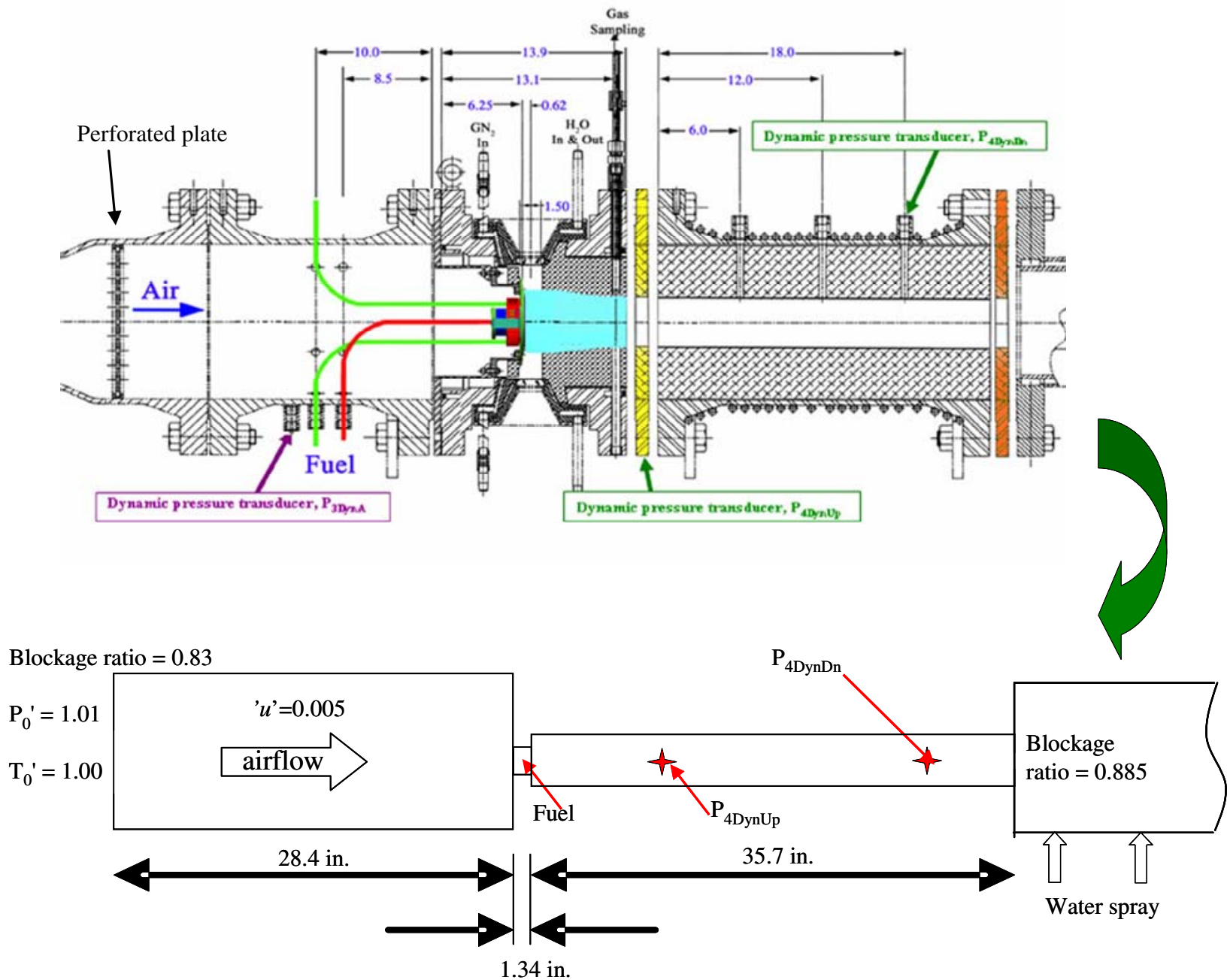

Figure 8.- Sectored 1-D simulation layout as related to the low emissions combustor prototype and rig.

As described in reference 17, the simulation requires the specification of a number of input parameters in order to successfully replicate a given combustor operating point. Since details of the simulation implementation are not the focus of the present paper, many of these parameters will not be discussed. However, two parameters are germane to the simulated results presented, and therefore require elucidation. The first is the reaction rate coefficient, $\mathrm{K}_{0}$, to which the single-species chemical reaction rate is proportional. The second is the maximum diffusion coefficient, $\alpha=\varepsilon_{t} / \mathrm{Re}^{*}$. Here, the Reynolds number, $\operatorname{Re}^{*}$ is defined as $\rho^{*} a^{*} L / \mu$, where $\rho$ is density, $a$ is the speed of sound, $L$ is combustor length, and $\mu$ is the molecular viscosity. The turbulent viscosity ratio, $\varepsilon_{t}$ is defined as the ratio of turbulent to molecular viscosity. The * superscript in these formulas denotes a reference state relevant to the operating point of interest. The diffusion coefficient precedes the diffusion terms (mass, momentum, and thermal energy) in the governing equations. The spatial distribution of this coefficient is prescribed. Values are generally kept small (i.e., inviscid) upstream of the reaction zone, and are enlarged to the maximum value in regions where the combustor flow recirculates. This is justified on the basis that recirculating eddies and similar multi-dimensional flowfield phenomena have area-averaged (i.e., one-dimensional) transport behaviors that can be modeled as diffusion processes. The nominal values of $\mathrm{K}_{0}$ and $\alpha$ used in the present simulation were 30 and 0.0015 , respectively. The parameters have no associated units because the simulation is coded in a nondimensional, or reference-scaled format. Both of these parameters are mentioned here because they are the only two in the simulation which may depend on changes in the 
operating pressure. No models are currently employed in the simulation to predict the pressure dependency; however, the possibility of such is relevant to the discussion of subsequent results.

\section{Simulation Results and Discussion}

Figure 9 shows the simulated code output from a numerical cell corresponding to the downstream pressure transducer location on the experimental rig. On the right is a time trace of the pressure. On the left is an amplitude spectrum obtained from $1.5 \mathrm{sec}$ of simulated data sampled at $5.0 \mathrm{kHz}$. The particular operating conditions are as follows: $\mathrm{FAR}=0.029$; inlet pressure, $\mathrm{P}_{3}=250$ psia; inlet temperature, $\mathrm{T}_{3}=1000^{\circ} \mathrm{F}$; and combustor airflow, $\mathrm{W}_{3 \mathrm{C}}=0.360 \mathrm{lb}_{\mathrm{m}} / \mathrm{s}$. This output should be compared to the bottom trace of figure 2 . The self-excited oscillation is clearly present. The simulated frequency of $514 \mathrm{~Hz}$ is within 5 percent of the experimentally measured value $(540 \mathrm{~Hz})$. The simulated amplitude of 1.16 psi is within 10 percent of the measured value (1.05 psi).

Results showing simulated and experimentally measured thermoacoustic oscillation amplitudes for two different operating conditions, as functions of fuel/air ratio are shown in figure 10. The two operating conditions have identical corrected air flow rates and inlet temperatures of $\mathrm{W}_{3 \mathrm{C}}=0.360 \mathrm{lb}_{\mathrm{m}} / \mathrm{s}$, and $\mathrm{T}_{3}=1000$ ${ }^{\circ} \mathrm{F}$ respectively; however, the operating pressures differ. Considering first the high pressure data (magenta and light blue square symbols), it is seen that the simulation and experiment show comparable amplitudes, and trend similarly. The instability amplitude increases with FAR for both. As noted in the discussion of test results (sec. III.E), this is an intuitive result (i.e., more heat release available with increasing FAR); however, it is not always borne out in practice due to changes in acoustic properties, heat release rates, and pressure/heat release phasing issues. As will be discussed later, the amplitude is highly sensitive to the assumed exit boundary conditions. Additional tuning of the exit blockage could have potentially matched the amplitude more exactly. However, for the simulation results shown here, an exact match in amplitude was not deemed as physically relevant as a similar amplitude and similar amplitude trend.
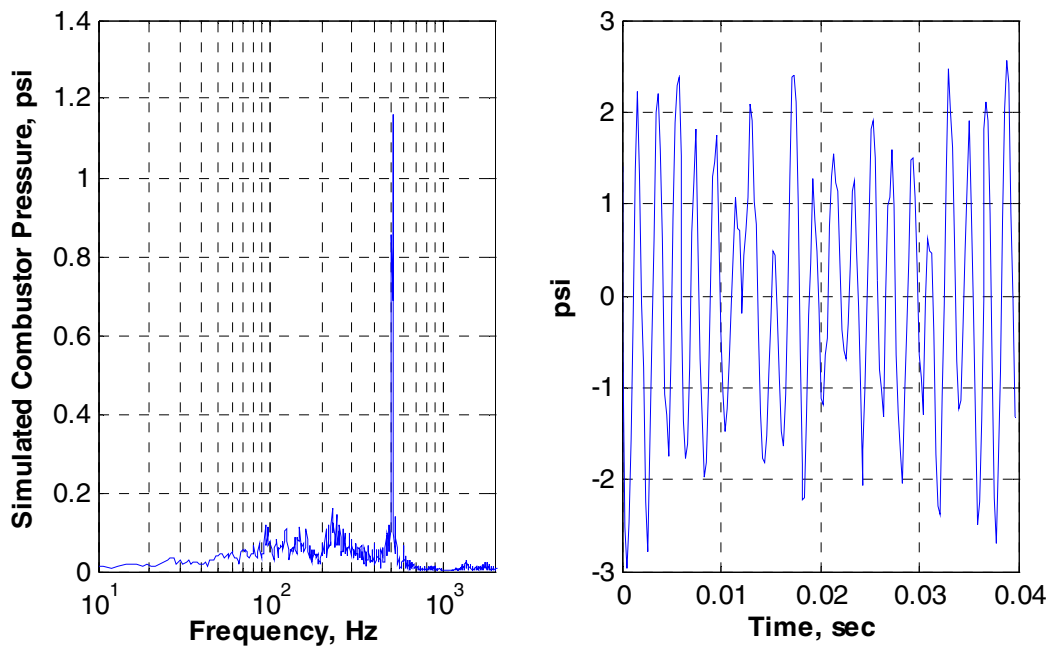

Figure 9.-Simulated thermoacoustic oscillation. The operating conditions simulated are $F A R=0.029, P_{3}=250 \mathrm{psia}, \mathrm{T}_{3}=1000^{\circ} \mathrm{F}, \mathrm{W}_{3 \mathrm{C}}=0.360 \mathrm{lb} / \mathrm{s}$. The amplitude spectrum utilized $1.5 \mathrm{sec}$ of simulated data. 


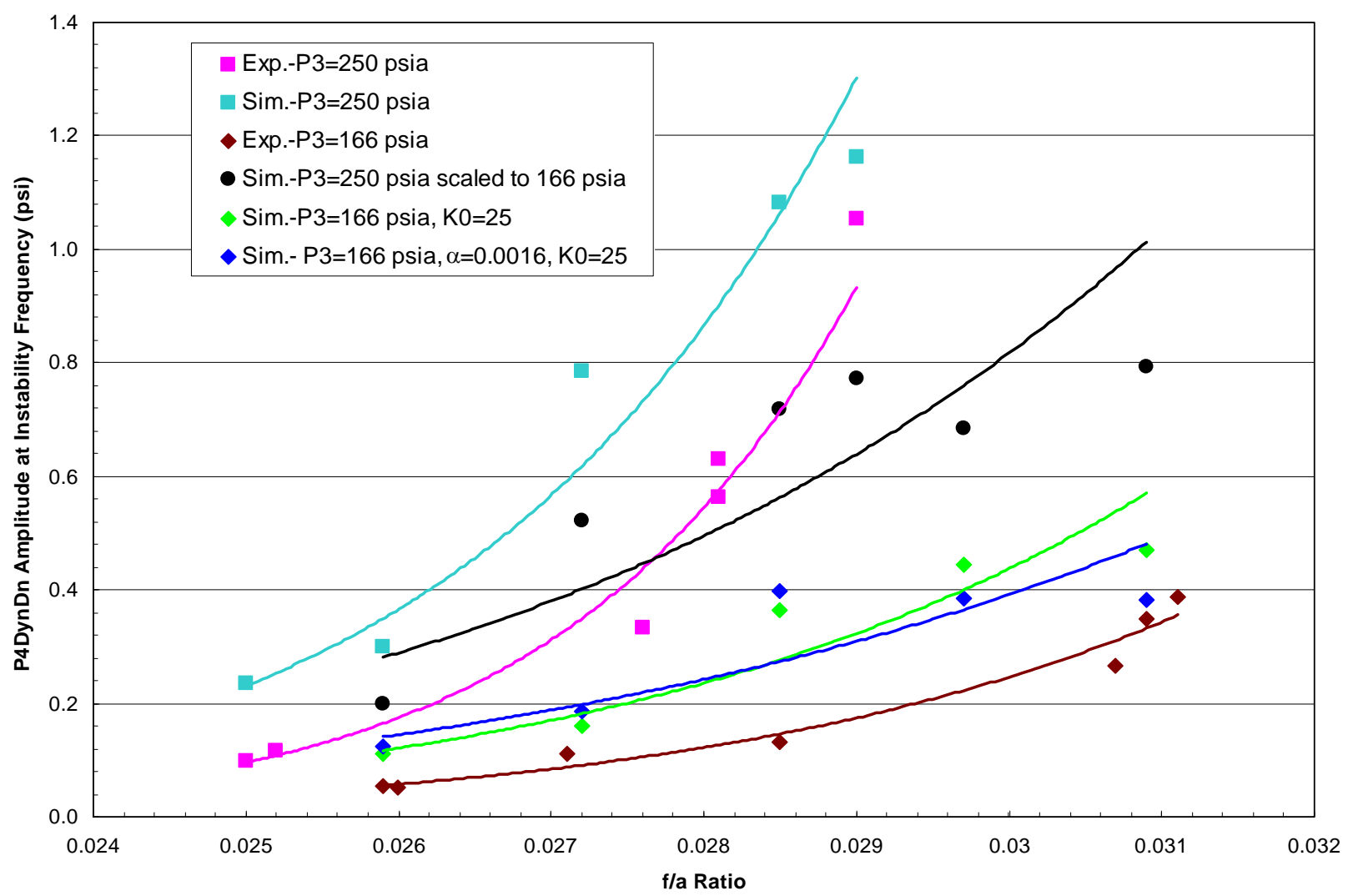

Figure 10.-Simulated and measured thermoacoustic oscillation amplitudes as functions of FAR for two operating conditions. For both conditions, $\mathrm{T}_{3}=1000^{\circ} \mathrm{F}$, and $\mathrm{W}_{3 \mathrm{C}}=0.360 \mathrm{lb}_{\mathrm{m}} / \mathrm{s}$. The simulated amplitudes were obtained from $1.5 \mathrm{sec}$ of simulated time.

Turning to the low pressure results, since the corrected flow rates and combustor temperatures are identical for the two operating conditions, it might be expected that the low pressure amplitudes could be predicted by simply scaling the high pressure data at a given FAR, that is $\mathrm{amp}_{\mathrm{lp}}=\mathrm{amp}_{\mathrm{hp}} * \mathrm{P}_{3 \mathrm{lp}} / \mathrm{P}_{3 \mathrm{hp}}$. Such a scaling is shown in figure 10 (black circular symbols). Although the simple scaling clearly shows a reduction in amplitudes, they are well above the experimentally observed values (brown diamond symbols) at all FAR's.

It was mentioned earlier, in the discussion of test results (sec. III.E), that reaction rates may be sensitive to operating pressure. In order to see if such a sensitivity may impact the simulation results, the rate constant $\mathrm{K}_{0}$ in the simulation was reduced from 30 to 25 (a 17 percent reduction). The results with reduced $\mathrm{K}_{0}$ are also shown in figure 10 (green diamond symbols). Here it is seen that the amplitudes of oscillations are decreased across the FAR range, and are much closer to the experimentally observed values.

A reduction in operating pressure at fixed $\mathrm{T}_{3}$ should also lead to a reduction in Reynolds number, and therefore an increase in $\alpha$, as defined above. In other words, diffusion should increase. As such, the maximum value of $\alpha$ in the simulation was increased from the nominal 0.0015 to 0.0016 (7 percent). The reduced value of $\mathrm{K}_{0}$ from the previous simulation run was maintained. These results are also shown in figure 10 (dark blue diamond symbols). Although the impact of such a change does not appear to be significant at the low values of FAR, is it notable at the higher values, where the simulated oscillation amplitudes now more closely match the experimental values. The trending of simulated and experimental results is nearly identical. 
The results of the parametric variations just described are by no means conclusive; however, they plausibly explain the relatively substantial drop in thermoacoustic pressure amplitude observed in the current rig, when the mean operating pressure was reduced.

The simulated and experimentally measured combustor instability frequencies are shown in figure 11 as functions of FAR for the two operating conditions just described. Although the simulated frequencies are consistently lower than the measured values, they are within 5 percent, and the trends are well matched. The rise in frequency with FAR is attributable to the accompanying rise in the combustor temperature, and therefore in the speed of sound. This concurs with the earlier experimental results discussion.

As mentioned earlier, the simulated instability amplitudes were very sensitive to the exit boundary impedance. This sensitivity is demonstrated in figure 12 which shows, for a single operating point, the simulated amplitude as a function of exit area blockage ratio, $\left(\mathrm{A}_{\text {blocked }} / \mathrm{A}_{\text {flame tube }}\right)$ and the experimentally observed amplitude. The operating point was at $\mathrm{P}_{3}=166$ psia, $\mathrm{T}_{3}=1000^{\circ} \mathrm{F}$, with $\mathrm{FAR}=0.0309$. For each change in blockage ratio, the exit back pressure was readjusted to maintain the corrected air flow rate. It can be seen from this plot that a small change in impedance or blockage ratio (1 percent), can triple the oscillation amplitude. Although the blockage boundary used to emulate the experimental water spray region is a crude approximation, the simulated amplitude sensitivity may be relevant. It was observed in the experiment that oscillation amplitudes were not always repeatable for the same flow conditions. One possible reason for this is that the water spray bars are set to limit the maximum exhaust gas temperature, but are neither set nor monitored for consistency. Therefore, variations in the water spray between test runs could have effectively altered the exit boundary of the experiment in much the same way that the simulated blockage ratio change does. Since the main purpose of the experiment was to monitor emissions formation, no particular attention was paid to acoustic boundary conditions such as this. However, for future testing, plans are to provide a physical area restriction at the end of the flame tube to provide a consistent exit boundary condition.

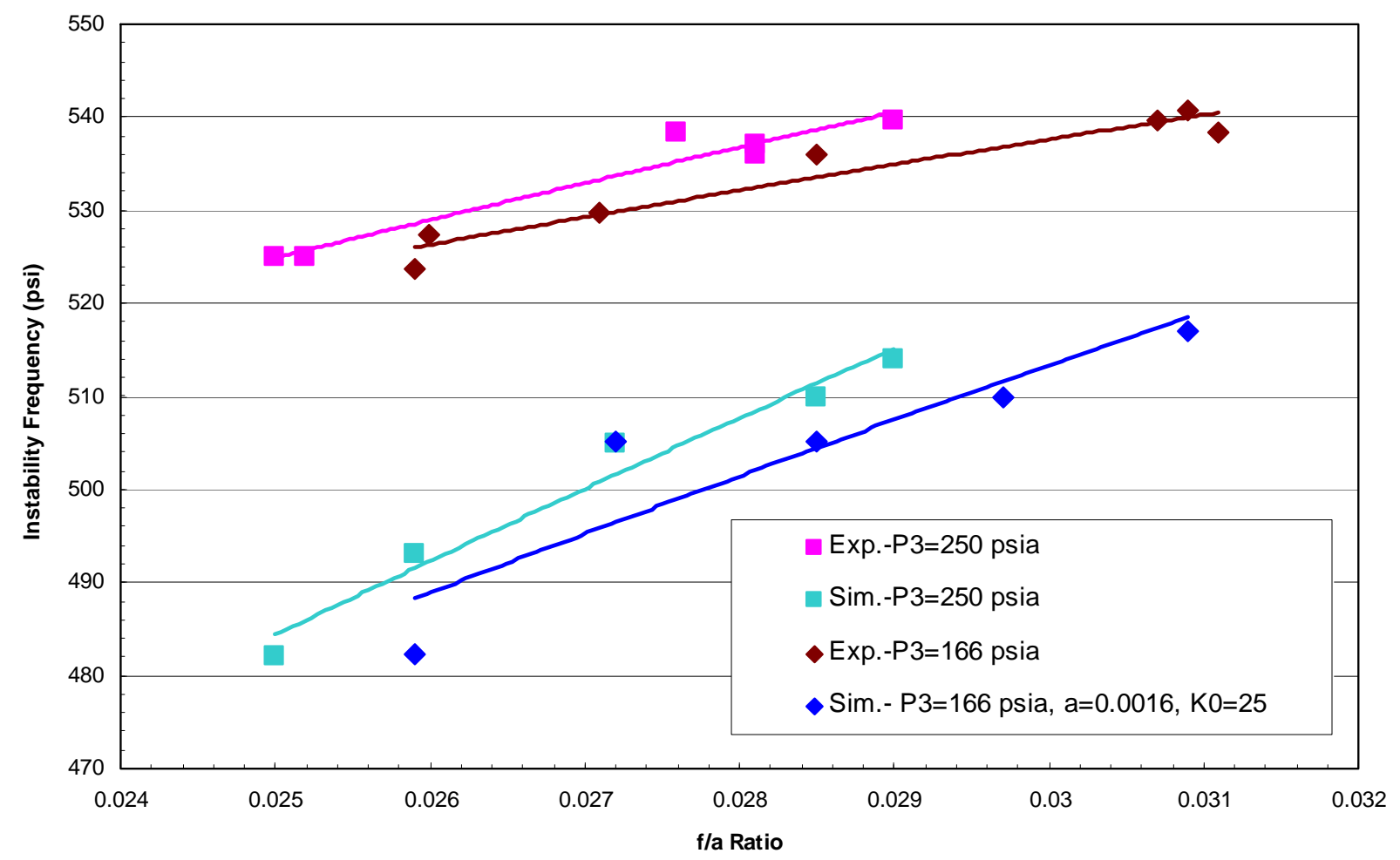

Figure 11.-Simulated and measured thermoacoustic oscillation frequencies as functions of FAR. Results are shown for two operating conditions. For both conditions, $T_{3}=1000{ }^{\circ} \mathrm{F}, \mathrm{W}_{3 \mathrm{C}}=0.360 \mathrm{lb} / \mathrm{s}$ 


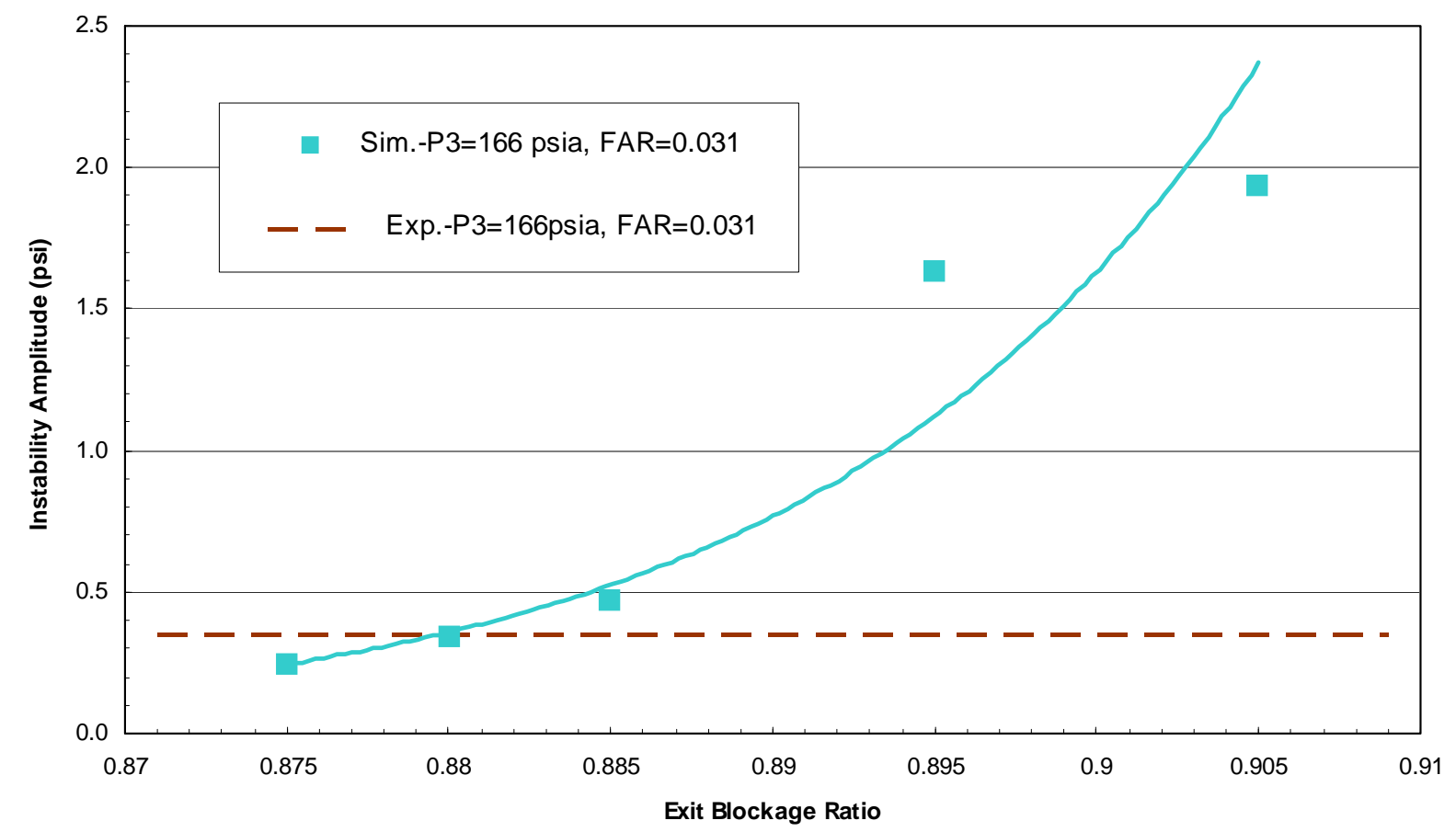

Figure 12.-Simulated thermoacoustic oscillation amplitude as a function of exit blockage ratio. Results are shown for a single operating point: $\mathrm{T}_{3}=1000^{\circ} \mathrm{F}, \mathrm{W}_{3 \mathrm{C}}=0.360 \mathrm{lb} / \mathrm{s}, \mathrm{P}_{3}=166 \mathrm{psia}, \mathrm{FAR}=0.0309$.

\section{Concluding Remarks}

Combustion instabilities were observed in an advanced, low emissions combustor prototype during experimental testing in a NASA Glenn combustion test stand. The instability behavior of the combustor has been characterized by operating the combustor at inlet pressures, inlet temperatures, airflows, and fuel/air ratios representative of operation within an aircraft gas turbine engine. The instability produced pressure oscillations within the combustor, and growth of the instability with increasing fuel flow prevented the combustor from being operated at full power conditions. Trends in the instability behavior have been noted and possible explanations for these trends provided. Plans are to use this advanced combustor prototype as a test bed for active control of combustion instability. A simulation method developed at NASA Glenn has been modified in order to replicate the experimentally observed combustion instability. The physics-based simulation uses a Sectored 1-D approach and provides timeaccurate results. The simulation captures the instability behavior of the combustor prototype and also the trends in instability versus operating condition. The simulation has provided further insights into the observed instability trends. Future plans are to use the simulation to investigate active control strategies for suppressing the combustion instabilities in the advanced, low emissions combustor prototype. These control strategies are then planned to be demonstrated experimentally with the combustor in the NASA Glenn combustion test facility.

\section{References}

1. Lefebvre, A.H.: Gas Turbine Combustion, 2nd edition, Taylor \& Francis, Philadelphia, 1999.

2. Mongia, H.; Held, T.; Hsiao, G; Pandalai, R.: "Challenges and Progress in Controlling Dynamics in Gas Turbine Combustors,” Journal of Propulsion and Power, vol. 19, no. 5, pp. 822-829, September-October 2003. 
3. Schadow, K.; Yang, V., Culick, F.; Rosfjord, T.; Sturgess, G.; Zinn, B.: “Active Combustion Control for Propulsion Systems,” AGARD Report 820, September 1997.

4. Zinn, B.T.; Neumeier, Y.: “An Overview of Active Control of Combustion Instabilities,” AIAA Paper 97-0461, January 1997.

5. McManus, K.R.; Magill, J.C.; Miller, M.F.; Allen, M.G.: “Closed-Loop System for Stability Control In Gas Turbine Combustors,” AIAA Paper 97-0463, January 1997.

6. Annaswamy, A.M.; El Rifai, O.M.; Fleifil, M.; Hathout, J.P.; Ghoniem, A.F.: “A Model-based Selftuning Controller for Thermoacoustic Instability,” in Combustion Science and Tech., vol. 135, pp. 213-240, 1998.

7. Hibshman, J.R.; Cohen, J.M.; Banaszuk, A.; Anderson, T.J.; Alholm, H.A.: “Active Control of Combustion Instability in a Liquid-Fueled Sector Combustor," presented at the International Gas Turbine \& Aeroengine Congress and Exhibition, June 1999. ASME Paper 99-GT-215.

8. Allgood, D.; Campos-Delgado, D.U.; Acharya, S.; and Zhoo, K.: “Acoustic Control of Thermoacoustic Instabilities Using Experimental Model-Based Controllers,” Proceedings of ASME Turbo Expo, New Orleans, LA, 2001.

9. Johnson, C. E.; Neumeier, Y.; Nuemaier, M.; Zinn, B. T.: "Demonstration of Active Control of Combustion Instabilities on a Full-Scale Gas Turbine Combustor,” Proceedings of ASME Turbo Expo, New Orleans, LA, 2001.

10. Kiel, B.: "Review of Advances in Combustion Control, Actuation, Sensing, Modeling and Related Technologies for Air Breathing Gas Turbines,” 39th Aerospace Sciences Meeting and Exhibit, Reno NV, AIAA 2001-0481, January 2001.

11. Barooah, P.; Anderson, T.J.; and Cohen, J.M.: “Active Combustion Instability Control with Spinning Valve Actuator,” ASME Turbo Expo 2002, Amsterdam, The Netherlands. ASME Paper GT-200230042, June 2002.

12. Cohen, J.; Proscia, W.; DeLaat, J.: "Characterization and Control of Aeroengine Combustion Instability: Pratt \& Whitney and NASA Experience,” Combustion Instabilities in Gas Turbine Engines: Operational Experience, Fundamental Mechanisms, and Modeling, eds. Timothy Lieuwen, Vigor Yang, AIAA, Reston, VA, 2005, pp. 113-145.

13. DeLaat, J.C.; Chang, C.T.: "Active Control of High Frequency Combustion Instability in Aircraft Gas-Turbine Engines,” 16th International Symposium on Airbreathing Engines, Cleveland, OH, ISABE-2003-1054, NASA/TM-2003-212611, September 2003.

14. Kopasakis, G.; DeLaat, J.; Chang, C.: "Validation of an Adaptive Combustion Instability Control Method for Gas-Turbine Engines,” 40th Joint Propulsion Conference and Exhibit, Ft. Lauderdale, FL, AIAA-2004-4028, NASA/TM-2004-213198, October 2004.

15. Le, D.K.; DeLaat, J.C.; Chang, C.T.; Vrnak, D.R.: "Model-Based Self-Tuning Multiscale Method for Combustion Control,” 41st Joint Propulsion Conference and Exhibit, Tucson, Arizona, July 10-13, 2005. AIAA-2005-3593.

16. Tacina, R.; Wey, C.; Laing, P.; Mansour, A.: “A Low NOx Lean-Direct Injection, Multipoint Integrated Module Combustor Concept for Advanced Aircraft Gas Turbines,” NASA/TM-2002211347, April 2002.

17. Paxson, D.: "A Sectored-One-Dimensional Model for Simulating Combustion Instabilities in Premix Combustors,” 38th Aerospace Sciences Meeting \& Exhibit. AIAA-2000-0313, NASA/TM-1999209771, January 2000. 


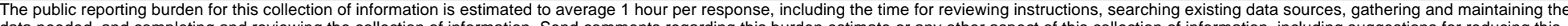

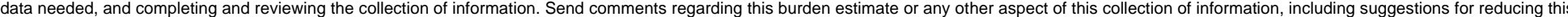

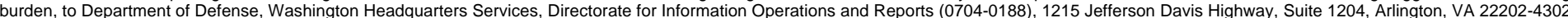

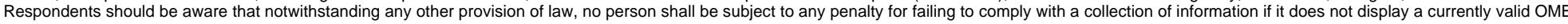
control number.

PLEASE DO NOT RETURN YOUR FORM TO THE ABOVE ADDRESS

\section{REPORT DATE (DD-MM- $Y Y Y Y)$ \\ 2. REPORT TYPE \\ 3. DATES COVERED (From - To)}

01-07-2008

\section{TITLE AND SUBTITLE}

Technical Memorandum

Characterization and Simulation of the Thermoacoustic Instability Behavior of an Advanced,

Low Emissions Combustor Prototype

\section{5a. CONTRACT NUMBER}

5b. GRANT NUMBER

5c. PROGRAM ELEMENT NUMBER

\section{AUTHOR(S)}

DeLaat, John, C.; Paxson, Daniel, E.

\section{5d. PROJECT NUMBER}

5e. TASK NUMBER

5f. WORK UNIT NUMBER

WBS 984754.02.07.03.19.04

\section{PERFORMING ORGANIZATION NAME(S) AND ADDRESS(ES)}

National Aeronautics and Space Administration

\section{PERFORMING ORGANIZATION} REPORT NUMBER

John H. Glenn Research Center at Lewis Field

E-16576

Cleveland, Ohio 44135-3191

\section{SPONSORING/MONITORING AGENCY NAME(S) AND ADDRESS(ES)}

National Aeronautics and Space Administration

Washington, DC 20546-0001

\section{SPONSORING/MONITORS ACRONYM(S) \\ NASA \\ 11. SPONSORING/MONITORING REPORT NUMBER \\ NASA/TM-2008-215291}

\section{DISTRIBUTION/AVAILABILITY STATEMENT}

Unclassified-Unlimited

Subject Category: 07

Available electronically at http://gltrs.grc.nasa.gov

This publication is available from the NASA Center for AeroSpace Information, 301-621-0390

\section{SUPPLEMENTARY NOTES}

\section{ABSTRACT}

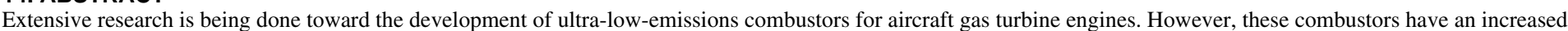

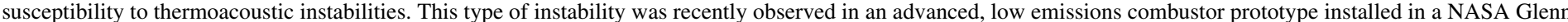

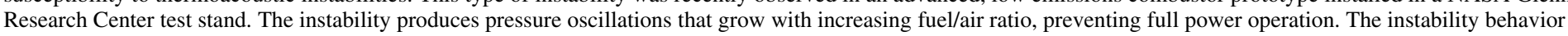

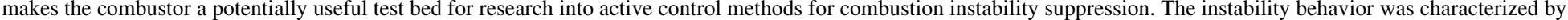

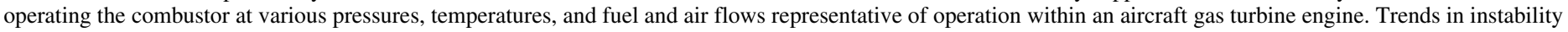

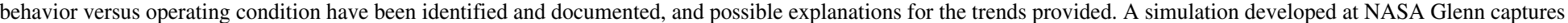

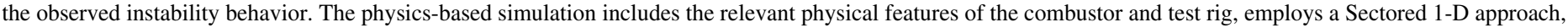

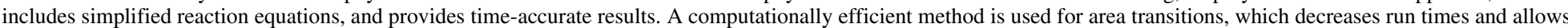

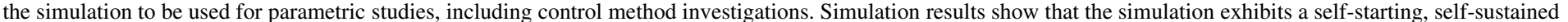

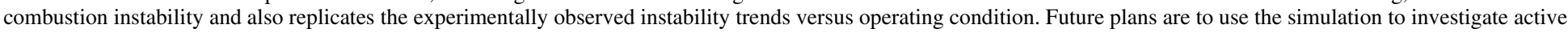

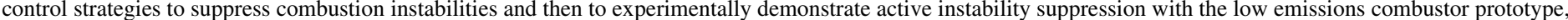
enabling full power, stable operation.

15. SUBJECT TERMS

Aircraft engines; Combustion stability; Computerized simulation; Combustion control; Engine control; Simulation; Control

\begin{tabular}{|c|c|c|c|}
\hline \multicolumn{3}{|c|}{ 16. SECURITY CLASSIFICATION OF: } & \multirow{2}{*}{$\begin{array}{l}\text { 17. LIMITATION OF } \\
\text { ABSTRACT } \\
\text { UU }\end{array}$} \\
\hline $\begin{array}{l}\text { a. REPORT } \\
\text { U }\end{array}$ & $\begin{array}{l}\text { b. ABSTRACT } \\
\text { U }\end{array}$ & $\begin{array}{l}\text { c. THIS } \\
\text { PAGE } \\
\text { U }\end{array}$ & \\
\hline
\end{tabular}

18. NUMBER
OF
PAGES
25

19a. NAME OF RESPONSIBLE PERSON STI Help Desk (email:help@sti.nasa.gov) 19b. TELEPHONE NUMBER (include area code) 301-621-0390 

